\title{
Semantic input/output matching for waste processing in industrial symbiosis
}

\author{
Nikolaos Trokanas*, Franjo Cecelja, Tara Raafat \\ Centre for Process and Information Systems Engineering, Faculty of Engineering and Physical Sciences, University of Surrey, Guildford GU2 7XH, \\ United Kingdom
}

\section{A R T I C L E I N F O}

Article history:

Received 30 September 2013

Received in revised form 6 February 2014

Accepted 9 February 2014

Available online 28 February 2014

Keywords:

Semantics

Ontology

Industrial symbiosis

Waste processing

\begin{abstract}
A B S T R A C T
Industrial symbiosis (IS) is a subdiscipline of Industrial Ecology that aims to bring together companies from different sectors to share resources, namely energy, materials, and water. The main goal of IS is to improve resource (materials, waste, energy) efficiency and lead to mutual environmental, financial and social benefits to participants.

In this paper we present a semantic approach for IS input/output matching. This approach is based on knowledge modelling and ontologies.

Ontologies are used to model all resources - waste, water, energy - along with details about their composition, characteristics (chemical and physical) and tacit knowledge about their flow.

The input/output matching algorithm presented enables the valorisation of resources through industrial symbiosis networks.
\end{abstract}

(C) 2014 Elsevier Ltd. All rights reserved.

\section{Introduction}

Industrial symbiosis (IS) is a subdiscipline of Industrial Ecology that aims to bring together companies from different sectors to share resources, namely energy, materials and water (Chertow, 2004; Jacobsen, 2006). The main goal of IS is to improve resource (materials, waste, energy) utilisation and provide mutual environmental, financial and social benefits to participants (Van Berkel, 2010). Benefits are generated by the reduced intake of virgin materials, reduced amount of waste (Chertow, 2007) being landfilled, reduced emissions (Jacobsen, 2006), job creation (Chertow, 2007) and/or innovation (Van Berkel, 2010).

As demonstrated, IS is a knowledge-intensive discipline (Davis, Nikolic, \& Dijkema, 2010). One of the key barriers in promoting IS is the difficulty in identifying new uses of waste (Chertow, 2007). Other main pieces of information required in promoting IS are the information about the composition of waste streams and the documentation of material flows (Allen, 2004). Consequently, the input/output matching is a significant tool in IS practice referring to formation of symbiotic networks (Chertow, 2000).

Tacit and explicit knowledge in a knowledge base about IS have been identified as a pre-requisite for the thriving evolution of IS into

\footnotetext{
* Corresponding author. Tel.: +4407411122451.

E-mail addresses: n.trokanas@surrey.ac.uk, n.trokanas@gmail.com (N. Trokanas).
}

common practice (Grant, Seager, Massard, \& Nies, 2010). Semantics and hence the opportunities offered by web technologies have been identified as potential solutions to mentioned barriers (Davis et al., 2010; Grant et al., 2010; Kraines et al., 2005).

In this paper we present a semantic approach for IS input/output matching. The approach is based on knowledge modelling and ontology engineering (Gruber, 1993). The use of ontologies allows modelling both tacit and explicit knowledge. It also offers standardisation in an off-market and off-spec subject, such as waste. The approach is formalised as a service and implemented as an automated web service (Cecelja et al., 2013), thus reducing costs for participants. Along with an appreciated comfort in using the service, automation also aims in motivating the participation of more industries and especially SMEs.

More specifically, ontologies are used to model the resources, i.e. waste, water, energy, along with details about their composition, properties (chemical and physical) and tacit knowledge about respective flows. Here, tacit knowledge is referred to as the knowledge captured from experience and professional intuition in waste treatment and industrial symbiosis by IS professionals. Material flows are identified from previous experience and domain expertise including IS, chemical engineering and process engineering, among others. Ontologies are also used for integrating processing technologies into a IS process in the form of the symbiotic network (Raafat, Trokanas, Cecelja, \& Bimi, 2013). Knowledge modelling also allows for the pre-assessment of some of the environmental indicators of IS, hence enabling better screening and serving as a 


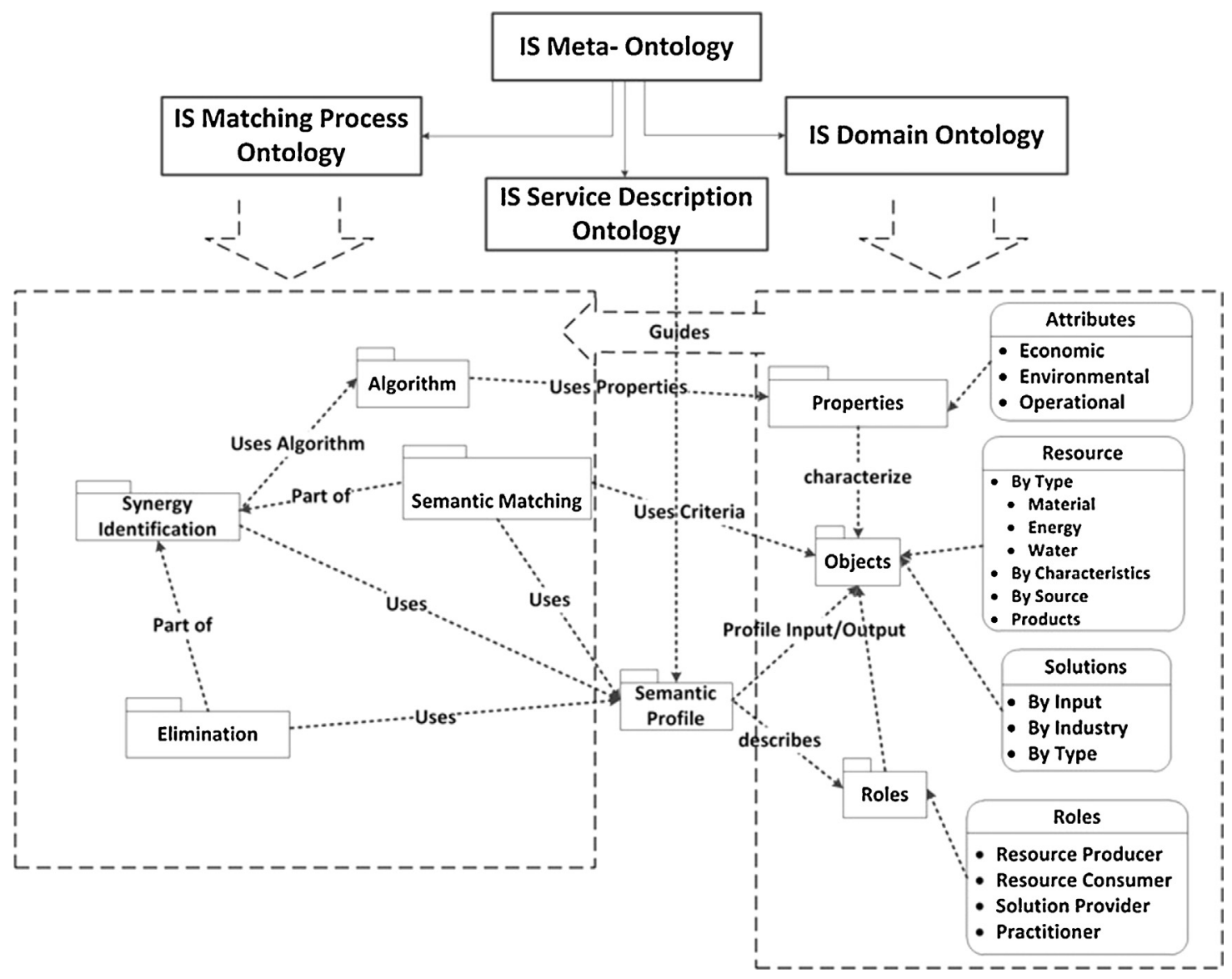

Fig. 1. IS ontology design.

useful decision making tool that further motivates participation (Trokanas, Cecelja, \& Raafat, 2013).

\section{Concepts and definitions}

Ontological engineering is employed to model and formalise the knowledge in the domain of IS. The proposed ontology consists of three high level modules (Fig. 1): (i) IS matching process ontology, (ii) IS domain ontology and (iii) IS service description ontology. The three modules form the IS meta-ontology. This work proposes a fully functional IS domain ontology adjusted to description of respective resources participating in IS as well as matching of resources to form IS networks.

The IS domain ontology has four levels of abstraction (Singh et al., 2007; Sokka, 2011), as illustrated in Fig. 2. These levels contribute to ontology design levels as defined in Ratafia-Brown, Manfredo, Hoffmann, and Ramezan (2002) and include (i) metalevel which defines general purpose concepts of the ontology that can be applied universally and have no dependence on specific domains, (ii) top level providing abstract concepts of the domain as well as the top-level relationships between these concepts, (iii) domain level which specifies the domain of IS, and (iv) instantiation level which is application specific level with the user profile instances linked directly to the IS semantic service description ontology.

The IS matching process ontology (Fig. 1) incorporates concepts relevant to the process of screening the symbiotic networks, in particular algorithms and mathematical techniques adapted and created to fulfil requirements of semantic matching for potential synergies.
In order for the algorithms to perform, all participants need to be semantically described. For that the IS service description ontology is employed. More precisely, all IS participating resources have a semantic profile presented as instances of IS domain ontology which is then implemented as instantiation of the service description ontology.

\subsection{Semantic description of resources}

In order to accurately reflect IS practice, the Resource concept in the IS domain ontology (Fig. 2) acts as the point of reference for all semantic service profile descriptions and the synergy identification activities. To this end, the concept Resource refers to materials, waste, energy, product and water that a user provides or requires. The Resource concept consists of four different classification streams: (i) classification bySource, (ii) classification byType, (iii) classification byProduct and (iv) classification byCharacteristic. Classification bySource is implemented using both existing classifications, e.g. The European Waste Catalogue (EWC) (European Commission, 2000) and purpose-made classifications representing specific types of waste imposed by the application. These classifications are used for the registration of a waste as a Resource or by-products of a processing technology. The nonstandard nature of waste makes it difficult to compare different types, hence imposing the use of a more standardised classification defining the composition of the waste. Classification byType itself includes three categorisations: (i) Materials, (ii) Energy and (iii) Water.

Materials category is used to address the problem of standardisation. This classification was developed such that it inherently invokes similarity for concepts that have structural proximity in the ontology. For example, different types of biomass are 


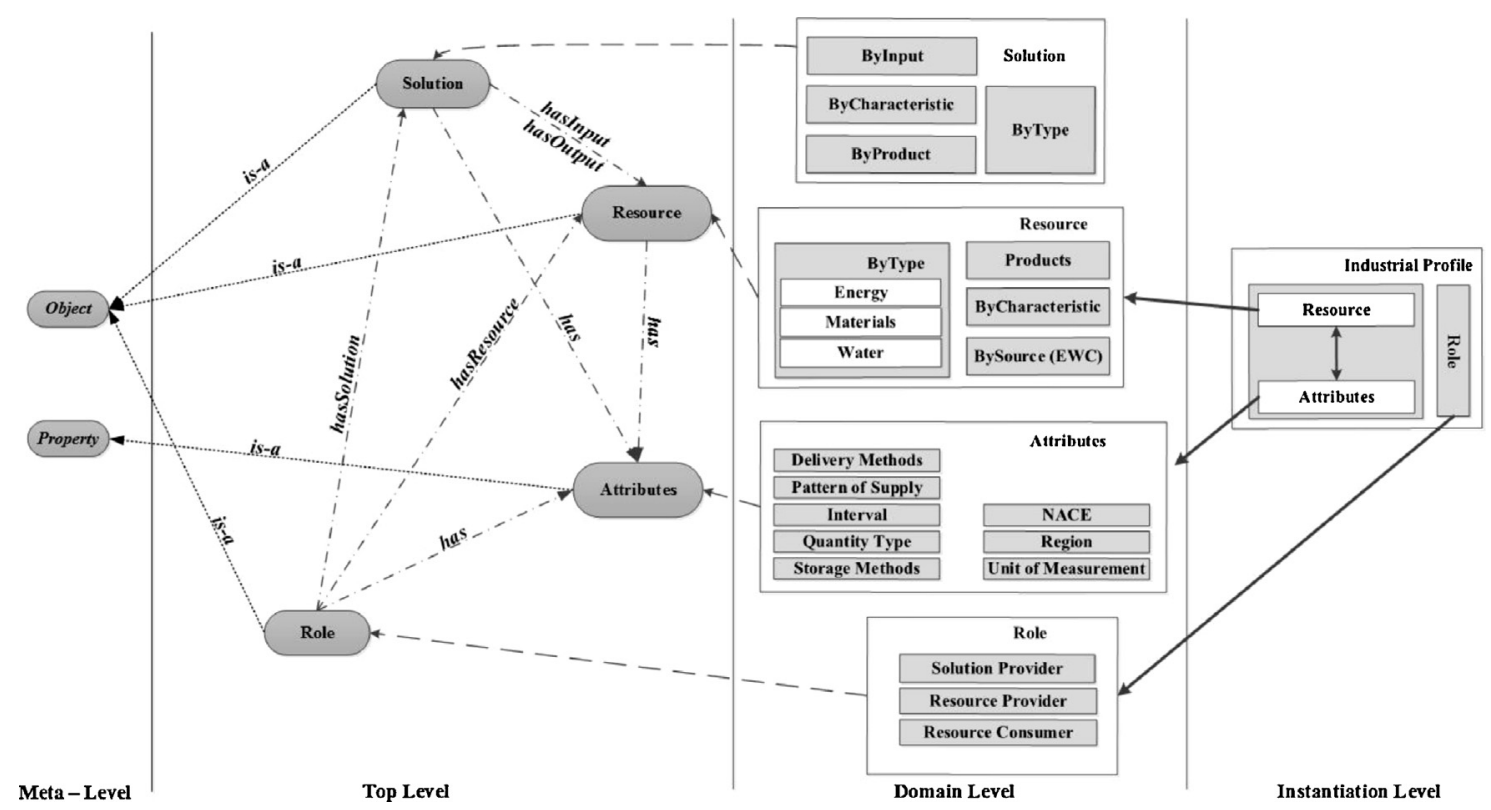

Fig. 2. Domain ontology structure.

interchangeable for biorefinery processes. However, Wood which is a type of LignocellulosicBiomass is more similar to Paper than other types of biomass such as PotatoPeel which is a type of StarchyBiomass (Fig. 3).

The Materials classification is also used to define the composition of waste and products as well as to define inputs, by-products and in some cases, products and by-products of processing technologies.

The Energy classification is specified as a resource but is also used to define energy requirements for processing technologies, whereas Water classification is used to define input or preprocessing conditions for some processing technologies.

The classification byProduct, is used to define the outcome (product) from processing technologies. It is also used by resource producers allowing for resource classification as products when the composition is not known. This classification is based on both existing product classifications, i.e. the United Nations Standard Products and Services Code ${ }^{\circledR}\left(\right.$ UNSPSC $\left.^{\circledR}\right)$, Central Product Classification (CPC) (UN, 2008), and on bespoke product classifications which depends on application. As with waste classifications, product classifications do not provide composition information and it is for that reason that the composition of products is defined through reference to materials classification.
The classification byCharacteristics refers to groups of concepts which share similar characteristics at a higher level in the ontology. This classification is designed to realise the benefits provided by the capability of the IS domain ontology to be inferred.

\subsection{Semantic description of processing technologies}

The concept Solutions represents processing technologies capable of material and energy conversion as well as all intermediary services such as transportation and storage (Fig. 2). This classification is analogous to the resource classification. It includes classifications by product, type, input and characteristics of the processing technologies. Each technology is characterised by its requirements and other properties as presented in Raafat et al. (2013). Again, the material classification acts as a reference through the definition of inputs and outputs of each processing technology. By introducing the concept Solutions in the ontology allows for the integration of processing technologies into the IS network, and hence enabling the development of complex symbiotic networks (Raafat et al., 2013).

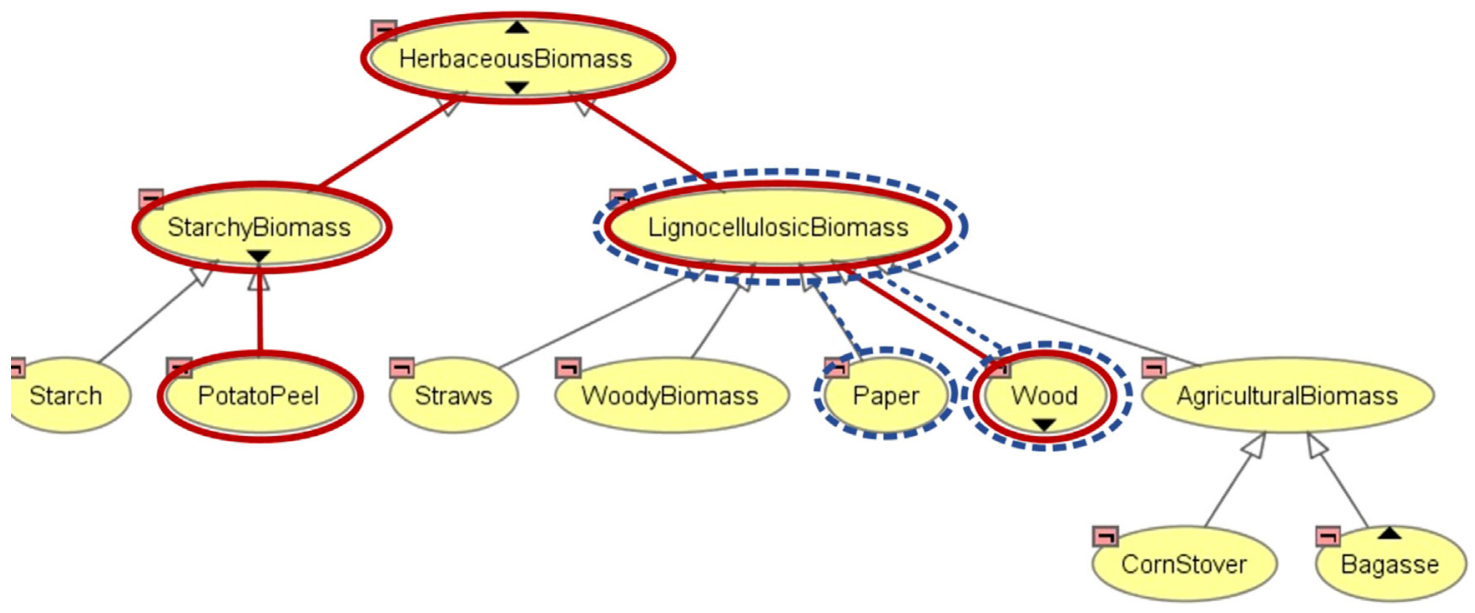

Fig. 3. Structural proximity of concepts. 
Table 1

The first two levels of the resource classification.

\begin{tabular}{ll}
\hline By type & By product \\
\hline Energy & Emissions \\
Cooling & CO \\
Electricity & CO2 \\
FuelGas & NOx \\
Heat & Particles \\
LiquidFuel & SO2 \\
SolidFuel & EnergyProducts \\
ThermalEnergy & Biofuels \\
Material & Biomass \\
Ceramic & Coal \\
Chemical & NaturalGas \\
Composite & Oil \\
Metal & OilShale \\
Mineral & Peat \\
OrganicMatterAndBiomass & MaterialProducts \\
Plastic & AgricultureForestyAndFishingProducts \\
Rock & ConstructionProducts \\
Water & FoodProductsBeveragesTobaccoTextiles \\
RainSurfaceWater & MetalProductsMachineryAndEquipment \\
SpringWater & OresMineralsElectricityGasAndWater \\
TapWater & OtherTrasportableGoods \\
UndergroundWater & \\
WasteWater & \\
\hline
\end{tabular}

\subsection{Classification and characterisation of resources}

The classification of resources offers a common reference for comparing resources and identifying semantic similarities needed for input/output matching. Following the same principles as in Raafat et al. (2013) for processing technology classifications, the goal is to create an exhaustive, relevant, easy to use and homogenous classification (Cherubini et al., 2009; McCarthy, 1995). As presented in Section 2.1, we use four classification streams for resources. Because of the large size of the ontology (more than 1600 concepts for resources), this paper only presents the first two levels of the streams ByType and ByProduct (Table 1). The third classification BySource is fully based on EWC classification (European Commission, 2000), while the fourth, ByCharacteristic, contains resources that have been reclassified based on certain characteristics such as biodegradability and hazardousness.

Along with classification of resources, this paper also proposes their characterisation. Each resource is characterised in terms of its economic, environmental and operational properties (Trokanas, Raafat, Cecelja, \& Kokossis, 2013). For the characterisation of resources we use both object and data type properties. Object properties are used for modelling of the tacit knowledge about the resources such as their composition (hasComposite) and industrial sectors (European Commission, 2008) that traditionally produce it (wasteProducedByIndustry). Data type properties are used for modelling of explicit knowledge describing resources. Here, data type properties have a twofold purpose: (i) collecting information from the participant and (ii) modelling the default values for known cases. Restrictions on properties are used to enable the latter. An example of restrictions on data type properties which define the embodied carbon, feedstock price and resource price of Polypropylene is shown in Fig. 4.

More details on the use of restrictions and their modelling and implementation are available in Trokanas, Raafat, Cecelja,

hasEmbodiedCarbon has 1.35 hasfeedstockPrice has 1000 hasResourcePrice has 845

Fig. 4. Restrictions used to define default values.
Kokossis, and Yang (2012) and Raafat et al. (2013). Some indicative data type and object properties along with their values ${ }^{1}$ are given in Table 2. This table illustrates the types of resources along with financial information (FeedstockPrice, RecyclatePrice) (letsrecycle.com, 2013), environmental information (EmbodiedCarbon, isBiodegradable) and IS-related operational information (hasComposite, wasteProducedByIndustry) (Alcorn \& Wood, 1998; Hammond, G., \& Jones, C., 2008).

\section{Input/output matching}

\subsection{Semantic profile for resources and technologies}

Semantic profile for resources and technologies and the process of ontology instantiation have been completed through the registration, a semantic profile of the user is created and implemented using OWL-S web service description framework (Martin et al., 2004). A user's profile contains all the information required for the matching process. The architecture of the semantic profile is given in Fig. 5. It contains the type of the resource (hasType), type of user (hasUserType), location (hasLocation), pattern of supply (hasPatternOfSupply) and other explicit information (isHazardous, validFrom, validTo, etc.).

Note that the semantic profile does not account for the processing technology. Instead, it contains a combination of resources identified as inputs and outputs of the registered processing technology, capitalising on the use of the Materials classification as a reference (Section 2.1).

\subsection{Algorithm for input/output matching}

The input/output matching is the process of establishing the semantic relevance between the profiles of the participants and hence to form symbiotic links. It is quantified by the similarity measure, which is calculated as a function of the explicit knowledge of a profile (quantity, location, availability) and the tacit knowledge (composition, associations, relevance, etc.). In consequence, the process of input/output matching is not only bound to identify direct matches. It can also semantically interpret the relationships that different concepts have with each other and it is therefore capable of suggesting alternative resources, identifying technologies that process similar types of resource or proposing different application for a resource.

In the current implementation, the process of input/output matching is performed in three stages (Fig. 6): (i) the stage of elimination,(ii) the stage of calculating the similarity measures including graph modelling, distance measurement and property matching and (iii) the stage of aggregation.

The elimination stage is introduced to minimise redundant matching and hence to computationally speed up the process. Three categories of elimination are introduced: (i) elimination based on requestor role, (ii) elimination based on the nature of the resource in terms of hazardousness, and (iii) elimination based on availability of resources. The requestor role is defined as one of: (i) resource provider, (ii) resource consumer and (iii) solution provider. All instances belonging to the requestor's group are logically eliminated from matching. Considering the fact that different user roles are defined by disjoint classes ${ }^{2}$ in ontology, every industry which is capable of both providing and processing a resource has to define two separate profiles under each role. Additionally, if the requestor is providing or asking for a hazardous material, all

\footnotetext{
1 http://www.recycleinme.com/scrapresources/PriceHome.aspx,

http://www.letsrecycle.com/prices, http://www.pricesofscrapmetal.co.uk/.

2 Disjoint classes are classes that cannot share any instances.
} 
Table 2

Indicative properties of resources.

\begin{tabular}{|c|c|c|c|c|c|c|}
\hline \multirow[t]{2}{*}{ Resource } & \multicolumn{4}{|c|}{ Datatype properties } & \multicolumn{2}{|l|}{ Object properties } \\
\hline & $\begin{array}{l}\text { Feedstock price } \\
(£ / \text { tonne })\end{array}$ & $\begin{array}{l}\text { Recyclate price } \\
\text { (£/tonne) }\end{array}$ & $\begin{array}{l}\text { Embodied carbon } \\
\left(\mathrm{kgCO}_{2} / \mathrm{kg}\right)\end{array}$ & $\begin{array}{l}\text { isBiodegradable } \\
\text { (boolean) }\end{array}$ & hasComposite & $\begin{array}{l}\text { wasteProduced } \\
\text { ByIndustry }\end{array}$ \\
\hline \multicolumn{7}{|l|}{ Type } \\
\hline \multicolumn{7}{|l|}{ Plastics } \\
\hline Thermoplastics & & & & False & & \\
\hline Polypropylene & 1810 & 600 & 3.9 & False & - & - \\
\hline Polyethylene & 965 & 230 & 1.94 & False & - & - \\
\hline PVC & 1360 & 700 & 2.41 & False & - & - \\
\hline Metals & & & & False & & \\
\hline NonFerrousMetals & & & & False & & \\
\hline Aluminium & 1092 & 500 & 8.24 & False & - & - \\
\hline Copper & 4400 & 1800 & 3 & False & - & - \\
\hline \multicolumn{7}{|l|}{ Product } \\
\hline PetroleumGases & & & & False & & \\
\hline Propylene & 1000 & 845 & 1.35 & False & - & - \\
\hline Butadiene & 1120 & - & - & False & - & - \\
\hline Ethylene & 950 & - & - & False & - & - \\
\hline \multicolumn{7}{|l|}{ Waste $^{\mathrm{a}}$} \\
\hline \multicolumn{7}{|l|}{ EWC0201 } \\
\hline EWC020102 & - & - & - & True & AnimalBiomass & \\
\hline EWC020103 & - & - & - & True & HerbaceousBiomass & \\
\hline EWC0303 & & & & & & $16,17,31$ \\
\hline EWC030301 & - & 15 & 0.2 & True & Wood, bark & $16,17,31$ \\
\hline EWC030307 & - & 55 & 1.00 & True & $\begin{array}{l}\text { Paper, } \\
\text { cardboard }\end{array}$ & $16,17,31$ \\
\hline
\end{tabular}

a EWC 020102 - animal-tissue waste, EWC 020103 - plant-tissue waste, EWC 030301 - waste bark and wood, EWC 030307 - mechanically separated rejects from pulping of waste paper and cardboard.

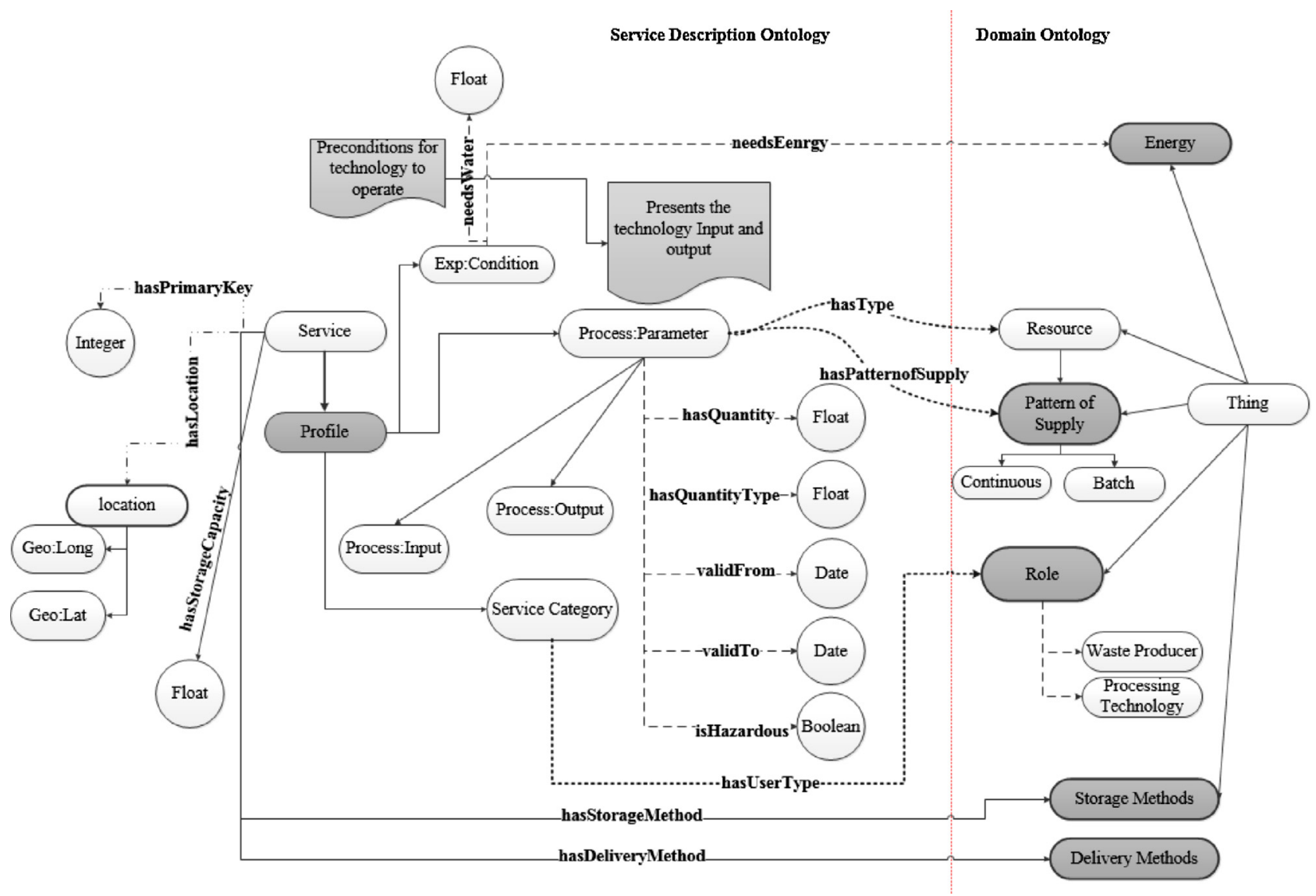

Fig. 5. Semantic profile architecture. 


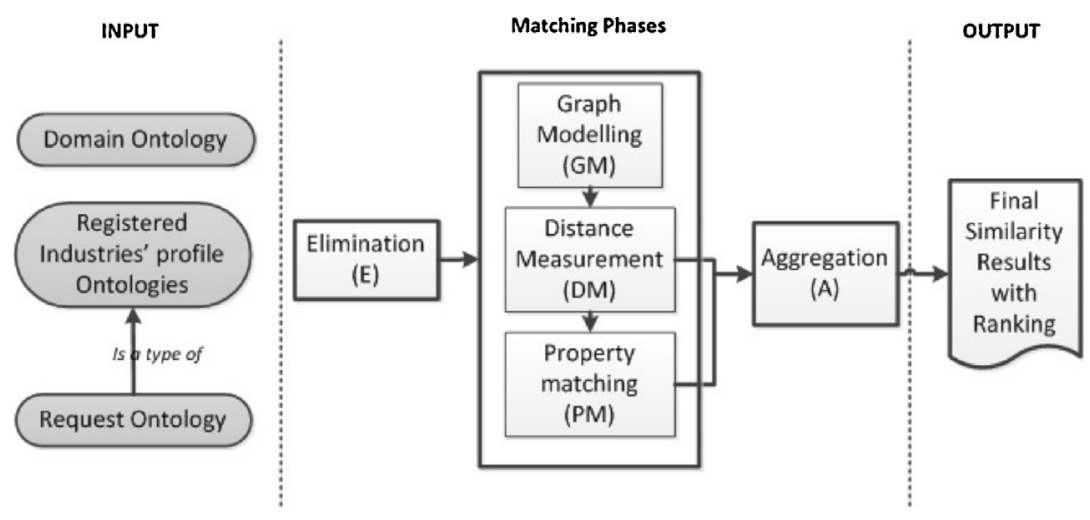

Fig. 6. Process of input/output matching.

instances which are not categorised as hazardous are eliminated. Availability, which is characterised by properties isValidFrom and isValidTo, is measured by the time overlap between the requestor and matched instances. Elimination occurs when there is no overlap.

The profiles which are not eliminated in the first stage, qualify for the stage 2, entailing the calculation of semantic similarity (Fig. 6). Semantic similarity determines comparison between requestor and other participants based on both tacit knowledge in the domain of IS provided by the IS experts and embedded in the ontology and explicit knowledge acquired from them in the course of instantiation of ontology. Semantic similarity consists of two quantifiable parts: (i) the distance measurement which depends on the structure of the ontology (Figs. 3 and 7), therefore incorporates tacit knowledge, and (ii) the vector similarity which is based on the values of properties (Fig. 4), therefore incorporates explicit information.

For the distance measurement (Fig. 6), the ontology is translated into a graph where concepts are represented by nodes and properties by arcs. The shortest distance between the two concepts is calculated from the graph by calculating the number of edges between them (Fig. 3). Distance is then converted to a similarity measure to allow for aggregation with the property similarity. It has to be mentioned here that IS relevant object properties between respective concepts are also accounted for the distance calculation. More specifically and in order to better represent IS practice, different weighting factors have been allocated to different object properties (Raafat et al., 2013). For example, the hasComposite property carries a weight of 0.6 , while the is-a property (hierarchy) carries only 0.5 (Fig. 7). Note that at this stage weights represent distance and therefore, higher weights imply higher distance and less similarity between the two concepts.

For calculation of the property similarity (Fig. 6) between requestor and user instances, four data properties are used (Table 3). In the present implementation, data properties are represented as vectors and property similarity is then calculated as a mean average of vector similarity combining cosine similarity and Euclidean similarity. As such, the absence of a property value, normally replaced by 0 , is not penalising calculated similarity more than semantically justifiable.

Given the data properties in Table 3, each profile is converted into a four-dimensional vector $\{$ Quantity, Distance, Availability, Pattern of Supply\}. The cosine similarity is calculated as a cosine of angle between the request vector and other user vectors. To relax

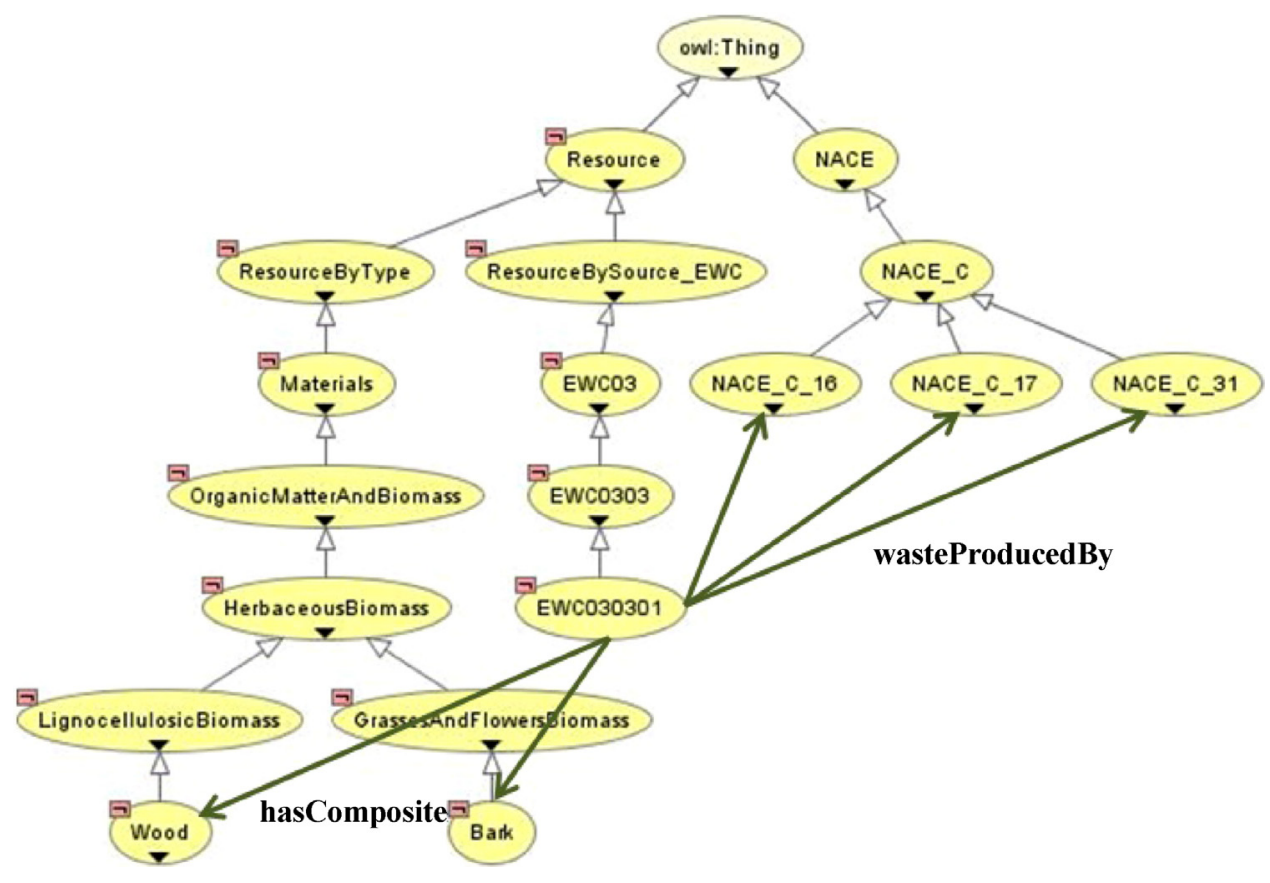

Fig. 7. Object properties example. 


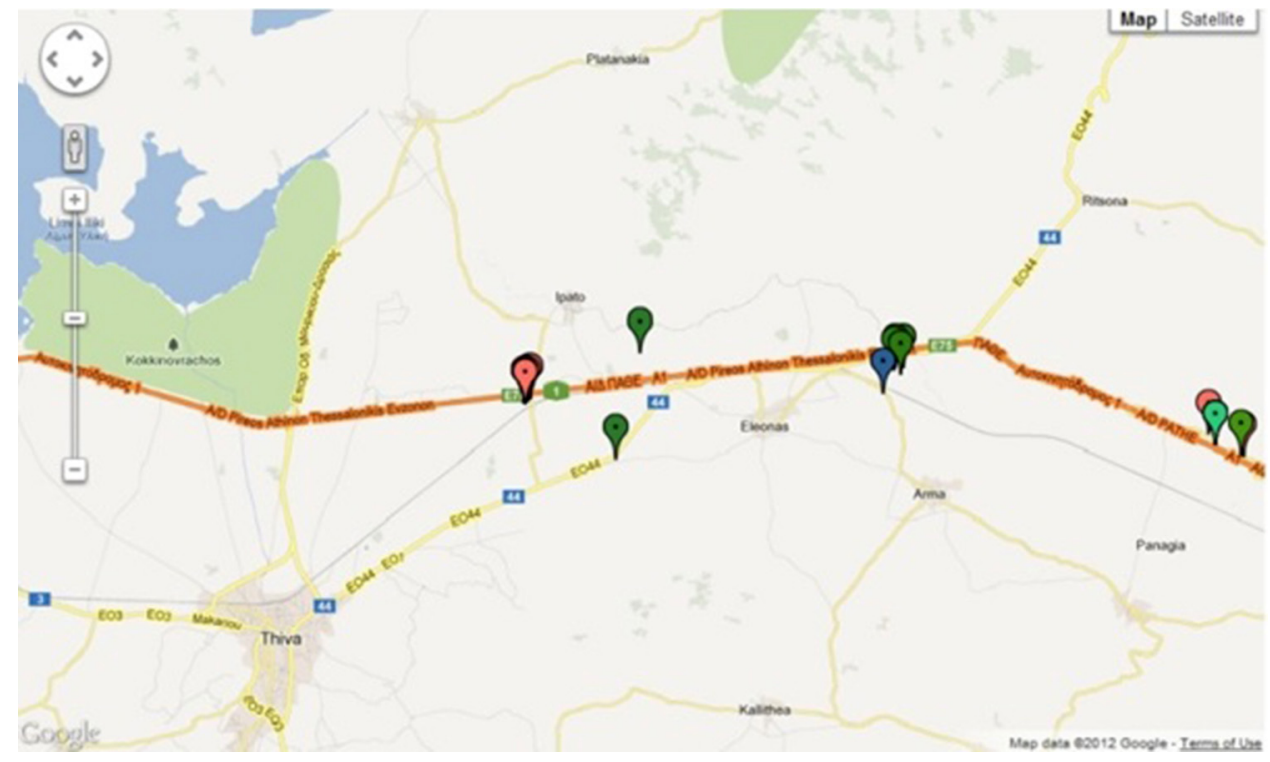

Fig. 8. Suggestions based on tacit knowledge.

the deviation introduced by the absence of a property, the distance and property similarity are aggregated together as a fuzzy weighted average as

Similarity $=\frac{\alpha \times \text { Distance }+\beta \times \text { Property similarity }}{\alpha+\beta}$

where $\alpha$ and $\beta$ are weighing parameters. In the current implementation, weighting parameters have been set to experiential values of $\alpha=0.6$ and $\beta=0.4$ to reflect IS practice, previous experience and area of application.

\subsection{Environmental performance of symbiosis}

A detailed characterisation of waste (Table 2) allows for deduction of even more information about a potential symbiotic synergy. More specifically, given the environmental nature of IS, the presented framework also enables the calculation of some environmental aspects of IS. Calculations rely on user input. However, when no user input is available, the already modelled values are used. Results are then re-ranked based on the environmental performance of the symbiosis.

Carbon savings are measured from the embodied carbon of the exchanged materials. By-products and re-used materials have lower embodied carbon values (Table 2) (Hammond, G. P., \& Jones, C., 2008; Monahan \& Powell, 2011). The replacement of a raw material with a by-product yields significant savings in carbon

Table 3

Properties participating in vector matching.

\begin{tabular}{|c|c|c|}
\hline Data property & Value type & Description \\
\hline Quantity & Float & $\begin{array}{l}\text { The exact value used in } \\
\text { the vector }\end{array}$ \\
\hline Location & Longitude and latitude & $\begin{array}{l}\text { Measured as } \\
\text { geographical distance } \\
\text { to the requester }\end{array}$ \\
\hline Availability & Date & $\begin{array}{l}\text { Is measured as the } \\
\text { percentage of overlap } \\
\text { with the availability } \\
\text { specified by the } \\
\text { requestor }\end{array}$ \\
\hline Pattern of supply & Predefined text & $\begin{array}{l}\text { Takes the value } 1 \text { for } \\
\text { continuous and } 2 \text { for } \\
\text { batch type of supply }\end{array}$ \\
\hline
\end{tabular}

emissions. Landfill diversion occurs in cases where a by-product is re-used instead of being landfilled. It simply refers to the quantity of the exchanged materials in these cases. Virgin materials saving occurs in cases where a raw material is replaced by a by-product.

\section{Case study}

Industry 1 is a pulp manufacturer that has 300 tonnes of waste per year. Instead of registering it following the EWC classification, they register it as a wood resource. Registration entails providing information that instantiate the ontology and create a service request. Along with the resource information, the user also provides information about their location and industry. The results that the user gets are presented in two stages: (i) first stage takes place before semantic similarity has been calculated, entails suggestions for waste valorisation and industrial collaborations, (ii) the second stage takes place after the calculation of semantic similarity and involves the presentation of semantic results to the user. Both stages are explained as follows.

Given the information about the industry and the location, the user receives feedback on possible partners in the local area. This information is extracted from the tacit knowledge embedded in the IS domain ontology and it is based on associations stemming from previous experience. This information is presented as a map (Fig. 8).

After providing details about the available resource, the user also gets suggestions on waste valorisation. In more detail, the user is presented with some of the modelled processing technologies that can process the registered resource (Fig. 9). For the user that has registered Wood, the suggestions include Anaerobic Digestion and Incineration Technologies. This step aims in promoting the reuse of resources even in cases when a symbiotic synergy is not formed. It can serve as a decision making or planning tool.

The second stage presents the results of the semantic matching process which includes all profiles already registered. Registered information used in matching (Table 3 ) includes the user type,

\section{Potential uses for "wood": - Anaerobic Digestion Technology - Incineration Technologies}

Fig. 9. Resource valorisation suggestions example. 
Table 4

Details of registered users.

\begin{tabular}{|c|c|c|c|c|c|c|c|c|}
\hline User ID & User type & Resource/solution & Quantity & ValidFrom & ValidTo & Latitude & Longitude & $\begin{array}{l}\text { Pattern of } \\
\text { supply }\end{array}$ \\
\hline 1 & $\mathrm{RP}$ & Wood & 300 & $07 / 06 / 2013$ & $06 / 04 / 2017$ & 38.330 & 23.674 & B \\
\hline 2 & $\mathrm{RP}$ & EWC030301 & 440 & $21 / 02 / 2014$ & $10 / 10 / 2017$ & 38.320 & 23.622 & B \\
\hline 3 & $\mathrm{RC}$ & EWC030104 & 230 & $21 / 10 / 2014$ & $13 / 09 / 2016$ & 38.310 & 23.558 & C \\
\hline 4 & $\mathrm{RC}$ & Wood & 700 & $18 / 02 / 2016$ & $25 / 10 / 2018$ & 38.339 & 23.609 & $\mathrm{C}$ \\
\hline 5 & $\mathrm{RP}$ & EWC030305 & 190 & $03 / 03 / 2015$ & $10 / 07 / 2017$ & 38.360 & 23.612 & $\mathrm{C}$ \\
\hline 6 & $\mathrm{RP}$ & Wooden packaging & 250 & $05 / 10 / 2015$ & $05 / 06 / 2018$ & 38.342 & 23.601 & $\mathrm{C}$ \\
\hline 7 & $\mathrm{RC}$ & EWC030307 & 560 & $16 / 10 / 2015$ & $24 / 07 / 2018$ & 38.326 & 23.506 & C \\
\hline 8 & SP & Anaerobic digestion & 1200 & $23 / 10 / 2015$ & $11 / 12 / 2017$ & 38.327 & 23.590 & B \\
\hline 9 & $\mathrm{RP}$ & EWC030101 & 100 & $10 / 12 / 2013$ & $12 / 05 / 2017$ & 38.346 & 23.607 & C \\
\hline 10 & SP & Wood incineration & 1000 & $26 / 07 / 2013$ & $08 / 06 / 2016$ & 38.322 & 23.613 & B \\
\hline
\end{tabular}

Table 5

Profiles matched to User 1.

\begin{tabular}{|c|c|c|c|c|c|c|c|c|}
\hline User ID & User Type & Resource/solution & Quantity & ValidFrom & ValidTo & Latitude & Longitude & $\begin{array}{l}\text { Pattern of } \\
\text { supply }\end{array}$ \\
\hline 3 & $\mathrm{RC}$ & EWC030104 & 230 & $21 / 10 / 2014$ & $13 / 09 / 2016$ & 38.310 & 23.558 & $\mathrm{C}$ \\
\hline 4 & $\mathrm{RC}$ & Wood & 700 & $18 / 02 / 2016$ & $25 / 10 / 2018$ & 38.339 & 23.609 & $\mathrm{C}$ \\
\hline 7 & $\mathrm{RC}$ & EWC030307 & 560 & $16 / 10 / 2015$ & $24 / 07 / 2018$ & 38.326 & 23.506 & $\mathrm{C}$ \\
\hline 8 & SP & Anaerobic digestion & 1200 & $23 / 10 / 2015$ & $11 / 12 / 2017$ & 38.327 & 23.590 & B \\
\hline 10 & SP & Wood incineration & 1000 & $26 / 07 / 2013$ & $08 / 06 / 2016$ & 38.322 & 23.613 & B \\
\hline
\end{tabular}

Table 6

Similarity results.

\begin{tabular}{lll}
\hline User ID & Resource/solution & Similarity \\
\hline 10 & Wood incineration & 0.88 \\
8 & Anaerobic digestion & 0.81 \\
4 & Wood & 0.78 \\
7 & EWC030307 & 0.78 \\
3 & EWC030104 & 0.71 \\
\hline
\end{tabular}

type of resource, available or required quantity, availability dates, location co-ordinates and pattern of supply (Table 4).

The profile of the request user is matched against existing profiles. The first step of the matching process is elimination as described in Section 3.2. The profiles that qualify for the next step for User 2, who is also the requestor, are shown in Table 5. These include only profiles with different user type and with availability dates (validFrom and ValidTo) that overlap.

Initially, the distance between the input and output concepts are calculated and translated to similarity. The values of the data properties (Table 5) are used to create vectors which are consequently compared as described in Section 3.2. The two similarity scores are aggregated giving the results provided in Table 6 .

As for the environmental aspects of the proposed synergies, the available details allow for the calculation of $\mathrm{CO}_{2}$ savings. These calculations are based on the embodied carbon values of the resources (Table 2). For synergies where an alternative resource is suggested the difference in tonnes of $\mathrm{CO}_{2}$ is presented to the user (Table 7). Also for these synergies, the amount of resource exchanged (quantity exchanged) is multiplied by the embodied carbon of the requested resource (EC of requested resource) and the embodied carbon of the suggested resource (EC of suggested resource). The difference ( $\mathrm{CO}_{2}$ saving) is presented to the user.

Given these results the potential synergies are re-ranked (Table 8 ) based on their environmental performance as described in Section 3.3.

The re-ranking of results aims in promoting waste processing by giving priority to synergies that offer environmental benefits.

\section{Conclusions}

The input/output matching algorithm presented enables the valorisation of resources through industrial symbiosis networks. Detailed modelling of resources and the use of semantics and ontology engineering offers numerous opportunities for better valorisation of resources. It also ameliorates the IS process. Semantic description of users allows for an automated input/output matching. Additional advantage of this approach is ability of partial matching. Synergies are assigned a semantic similarity score which

Table 7

Environmental indicators.

\begin{tabular}{|c|c|c|c|c|c|c|c|c|}
\hline User ID & $\begin{array}{l}\text { Suggested } \\
\text { resource }\end{array}$ & $\begin{array}{l}\text { Requested } \\
\text { resource }\end{array}$ & $\begin{array}{l}\text { Quantity } \\
\text { exchanged }\end{array}$ & $\begin{array}{l}\text { EC of suggested } \\
\text { resource }\end{array}$ & $\begin{array}{l}\text { EC of requested } \\
\text { resource }\end{array}$ & $\begin{array}{l}\text { Total EC } \\
\text { (requested) }\end{array}$ & $\begin{array}{l}\text { Total EC } \\
\text { (suggested) }\end{array}$ & $\begin{array}{l}\mathrm{CO}_{2} \text { saving } \\
\text { (tonCO } \mathrm{CO}_{2} \text { ) }\end{array}$ \\
\hline 4 & Wood waste & Wood & 440 & 0.2 & 0.46 & 202.4 & 88 & 114.4 \\
\hline 7 & Wood waste & EWC030307 & 440 & 0.2 & 1.00 & 440 & 88 & 352 \\
\hline
\end{tabular}

Table 8

Environmental results re-ranked.

\begin{tabular}{|c|c|c|c|c|c|}
\hline User ID & Resource/solution & Similarity & $\mathrm{CO}_{2}$ saving & $\begin{array}{l}\text { Landfill } \\
\text { diversion }\end{array}$ & $\begin{array}{l}\text { Virgin materials } \\
\text { saved }\end{array}$ \\
\hline 7 & EWC030307 & 0.78 & 352 & - & - \\
\hline 4 & Wood & 0.78 & 114.4 & 440 & 440 \\
\hline 10 & Wood incineration & 0.88 & 0 & - & - \\
\hline 8 & Anaerobic digestion & 0.81 & 0 & - & - \\
\hline 3 & EWC030104 & 0.71 & 0 & - & - \\
\hline
\end{tabular}


is calculated from information provided by the user and modelled in the ontology. Partial matching enables the identification of waste/resources processing opportunities beyond established practice and which would otherwise be ignored. Standardisation of a resource classification has been proposed and demonstrated. The presented ontology provides a common vocabulary. The level of information integrated in the ontology also allows the calculation of environmental, economic and operational indicators that serve as a useful tool for decision making.

\section{Appendix A. Properties characterising resources}

\begin{tabular}{ll}
\hline Relationship & Description \\
\hline hasPatternOfSupply & Batch or continuous operation of the \\
technology & Link between resources and industry sectors \\
for the integration of tacit knowledge about & the use of resources in different industries \\
Inverse relation of hasApplicationIn, used for & intelligent recommendations \\
canUse & Links resources to the QuantityType attribute \\
concept. The concept is about the physical & form of the resource (solid, liquid, etc.) \\
hasQuantityType & $\begin{array}{l}\text { Relation used to provide information about the } \\
\text { composition of products and waste types }\end{array}$ \\
hasComposite & The inverse of the above \\
Inverse relation of canProcess. Used for tacit \\
knowledge modelling for resource processing \\
kanBeprocessedBy
\end{tabular}

\section{Appendix B. Materials classification}

\begin{tabular}{|c|c|}
\hline Concepts & Description \\
\hline Resource & $\begin{array}{l}\text { Resource in IS contains materials, wastes, } \\
\text { water, energy, etc. }\end{array}$ \\
\hline ResourceByType & $\begin{array}{l}\text { Resources that can be naturally classified by } \\
\text { their type }\end{array}$ \\
\hline Materials & $\begin{array}{l}\text { The substance or substances out of which a } \\
\text { thing is or can be made }\end{array}$ \\
\hline Plastics & $\begin{array}{l}\text { This concept ranges from synthetic plastics } \\
\text { and elastomers to natural biopolymers }\end{array}$ \\
\hline RubberAndElastomers & All rubber and elastomer materials \\
\hline Thermoplastics & $\begin{array}{l}\text { Polymers that become moldable or pliable } \\
\text { above a certain temperature and returns to a } \\
\text { solid state upon cooling }\end{array}$ \\
\hline Thermosets & Polymers that irreversibly cures \\
\hline Metals & $\begin{array}{l}\text { Solid materials which are typically hard, shiny, } \\
\text { malleable, fusible, and ductile, with good } \\
\text { electrical and thermal conductivity. Includes } \\
\text { ferrous and non-ferrous metals and alloys }\end{array}$ \\
\hline NonFerrousMetalsAndAlloys & Metals and alloys that contain iron \\
\hline
\end{tabular}

\begin{tabular}{|c|c|}
\hline Concepts & Description \\
\hline FerrousMetalsAndAlloys & Metals and alloys that do not contain iron \\
\hline Ceramics & $\begin{array}{l}\text { Inorganic, non-metallic materials generally } \\
\text { made using clay and other earthen materials } \\
\text { through heat and cooling }\end{array}$ \\
\hline CementAndConcrete & Cement and concrete materials \\
\hline Clay & All clay minerals \\
\hline Glass & All types of glass \\
\hline Chemicals & $\begin{array}{l}\text { Any material with a definite chemical } \\
\text { composition }\end{array}$ \\
\hline ChemicalElements & Classification of all chemical elements \\
\hline Compounds & $\begin{array}{l}\text { Chemical substances consisting of two or more } \\
\text { different chemical elements }\end{array}$ \\
\hline InorganicChemicals & $\begin{array}{l}\text { Chemicals that lack carbon and hydrogen } \\
\text { atoms }\end{array}$ \\
\hline InorganicConstituents & $\begin{array}{l}\text { Constituents that lack carbon and hydrogen } \\
\text { atoms (e.g. ash) }\end{array}$ \\
\hline OrganicChemicals & Chemicals that contain carbon \\
\hline Minerals & $\begin{array}{l}\text { A mineral is a naturally occurring inorganic } \\
\text { solid, with a definite chemical composition, } \\
\text { and an ordered atomic arrangement }\end{array}$ \\
\hline Composites & $\begin{array}{l}\text { Naturally occurring or engineered materials } \\
\text { made from two or more constituents }\end{array}$ \\
\hline OrganicMatter & $\begin{array}{l}\text { Matter that comes from a once living organism } \\
\text { such as plants and animals }\end{array}$ \\
\hline AnimalBiomass & Biomass originating from animals \\
\hline AqueousBiomass & Biomass originating from the ocean \\
\hline HerbaceousBiomass & Biomass originating from plants \\
\hline Rocks & $\begin{array}{l}\text { The solid mineral materials forming part of the } \\
\text { surface of the earth and other planets }\end{array}$ \\
\hline Igneous & $\begin{array}{l}\text { Rocks formed through the cooling and } \\
\text { solidification of magma and lava }\end{array}$ \\
\hline Metamorphic & $\begin{array}{l}\text { Rocks formed from the transformation of } \\
\text { existing rock types }\end{array}$ \\
\hline Sedimentary & Rocks formed by the deposition of materials \\
\hline Energy & Usable heat or power \\
\hline Electricity & $\begin{array}{l}\text { The supply of electric current to a house or } \\
\text { other building for heating, lighting, or } \\
\text { powering appliances }\end{array}$ \\
\hline Heat & $\begin{array}{l}\text { The transfer of energy from one body to } \\
\text { another as a result of a difference in } \\
\text { temperature or a change in phase }\end{array}$ \\
\hline Water & $\begin{array}{l}\text { A clear, colourless, odourless, and tasteless } \\
\text { liquid, } \mathrm{H}_{2} \mathrm{O}\end{array}$ \\
\hline ResourceBySource(EWC) & $\begin{array}{l}\text { Based on EWC - waste classification based on } \\
\text { the source process }\end{array}$ \\
\hline Products & $\begin{array}{l}\text { The totality of goods that can be made } \\
\text { available by industries }\end{array}$ \\
\hline EnergyProducts & $\begin{array}{l}\text { Goods that can be used for the generation of } \\
\text { energy }\end{array}$ \\
\hline Biomass & Organic matter used as a fuel \\
\hline Biofuels & Fuels derived directly from living matter \\
\hline Coal & $\begin{array}{l}\text { A combustible black or dark brown rock } \\
\text { consisting mainly of carbonised plant matter, } \\
\text { found mainly in underground deposits and } \\
\text { widely used as fuel }\end{array}$ \\
\hline NaturalGas & $\begin{array}{l}\text { Flammable gas, consisting largely of methane } \\
\text { and other hydrocarbons }\end{array}$ \\
\hline Oil & A viscous liquid derived from petroleum \\
\hline OilShale & $\begin{array}{l}\text { Fine-grained sedimentary rock from which oil } \\
\text { can be extracted }\end{array}$ \\
\hline Peat & $\begin{array}{l}\text { A brown, soil-like material, consisting of partly } \\
\text { decomposed vegetable matter }\end{array}$ \\
\hline MaterialProducts & $\begin{array}{l}\text { All other goods, not included in class } \\
\text { EnergyProducts }\end{array}$ \\
\hline ResourceByCharacteristic & $\begin{array}{l}\text { Resources classified based on important } \\
\text { physical or chemical properties }\end{array}$ \\
\hline BiodegradableResource & $\begin{array}{l}\text { Resources that are capable of decaying through } \\
\text { the action of living organisms }\end{array}$ \\
\hline CombustibleResources & $\begin{array}{l}\text { Resources that are capable of igniting or } \\
\text { burning }\end{array}$ \\
\hline
\end{tabular}

\section{References}

Alcorn, A., \& Wood, P. (1998). New Zealand building materials embodied energy coefficients database volume II - coefficients. Centre for Building Performance Research, Victoria University of Wellington. 
Allen, D. T. (2004). An industrial ecology: Material flows and engineering design. In Sustainable development in practice: Case studies for engineers and scientists. John Wiley \& Sons, Inc.

Cecelja, F., Raafat, T. Trokanas, N., Innes, S., Yang, A., Smith, M., et al. (2012). e-Symbiosis: Technology-enabled support for industrial symbiosis targeting SMEs and innovation. In proceeding of: 18th Greening of Industry Network. Sweden: Linkoping. Available at: http://gin.confex.com/gin/2012/ webprogram/Manuscript/Paper3777/GIN2012Paper\%20Kokossis.pdf

Chertow, M. R. (2000). Industrial symbiosis: Literature and taxonomy. Annual Review of Energy and the Environment, 25(1), 313-337.

Chertow, M. R. (2004). Industrial symbiosis. Encyclopedia of Energy (vol. 3).

Chertow, M. R. (2007). Uncovering industrial symbiosis. Journal of Industrial Ecology, 11(1), 11-30.

Cherubini, F., Jungmeier, G., Wellisch, M., Willke, T., Skiadas, I., Van Ree, R., de Jong, E., et al. (2009). Toward a common classification approach for biorefinery systems. Biofuels, Bioproducts and Biorefining, 3(5), 534-546.

Davis, C., Nikolic, I., \& Dijkema, G. P.(2010). Industrial Ecology 2.0. Journal of Industrial Ecology, 14(5), 707-726.

European Commission. (2000). Commission Decision 2000/532/EC replacing Decision 94/3/EC establishing a list of wastes pursuant to Article 1 (a) of Council Directive 75/442/EEC on waste and Council Decision 94/904/EC establishing a list of hazardous waste pursuant to Article 1 (4) of Council Directive 91/689/EEC on hazardous waste. Official Journal of the European Communities, 3-24.

European Commission. (2008). NACE Rev. 2 - Statistical classification of economic activities in the European Community. Luxembourg: Office for Official Publications of the European Communities.

Grant, G. B., Seager, T. P., Massard, G., \& Nies, L. (2010). Information and communication technology for industrial symbiosis. Journal of Industrial Ecology, 14(5), 740-753.

Gruber, T. R. (1993). A translation approach to portable ontology specifications. Knowledge Acquisition, 5(2), 199-220.

Hammond, G., \& Jones, C. (2008). Inventory of carbon \& energy: ICE. Sustainable Energy Research Team. Department of Mechanical Engineering, University of Bath.

Hammond, G. P., \& Jones, C. (2008). Embodied energy and carbon in construction materials. Proceedings of the Institution of Civil Engineers - Energy, 161(2), 87-98.

Jacobsen, N. B. (2006). Industrial symbiosis in Kalundborg, Denmark: A quantitative assessment of economic and environmental aspects. Journal of Industrial Ecology, 10(1-2), 239-255
Kraines, S., Batres, R., Koyama, M., Wallace, D., Komiyama, H., et al. (2005) Internet-based integrated environmental assessment using ontologies to share computational models. Journal of Industrial Ecology, 9(3), 31-50.

letsrecycle.com. (2013). Prices - letsrecycle.com. Available at: http://www letsrecycle.com/prices (Accessed 26.09.13)

Martin, D., Burstein, M., Hobbs, J., Lassila, O., McDermott, D., McIlraith, S., et al. (2004) OWL-S: Semantic markup for web services (vol. 22) W3C Member submission.

McCarthy, I. (1995). Manufacturing classification: Lessons from organizational systematics and biological taxonomy. Integrated Manufacturing Systems, 6(6), 37-48.

Monahan, J., \& Powell, J. (2011). An embodied carbon and energy analysis of modern methods of construction in housing: A case study using a lifecycle assessment framework. Energy and Buildings, 43(1), 179-188.

Raafat, T., Trokanas, N., Cecelja, F., \& Bimi, X. (2013). An ontological approach towards enabling processing technologies participation in industrial symbiosis. Computers \& Chemical Engineering, 59, 33-46. http://dx.doi.org/10.1016/ j.compchemeng.2013.03.022

Ratafia-Brown, J., Manfredo, L., Hoffmann, J., \& Ramezan, M. (2002). Major environmental aspects of gasification-based power generation technologies, Prepared for DOE/NETL.

Singh, A., Lou, H., Yaws, C., Hopper, J., Pike, R., et al. (2007). Environmental impact assessment of different design schemes of an industrial ecosystem. Resources, Conservation and Recycling, 51(2), 294-313.

Sokka, L. (2011). Local systems, global impacts: Using life cycle assessment to analyse the potential and constraints of industrial symbioses. VTT Publications.

Trokanas, N., Cecelja, F., \& Raafat, T. (2013). Semantic approach for the preassessment of environmental indicators of industrial symbiosis. Journal of Cleaner Production, http://dx.doi.org/10.1016/j.jclepro.2013.12.046

Trokanas, N., Raafat, T., Cecelja, F., \& Kokossis, A. (2013). OFIS - ontological framework for industrial symbiosis. In Computer aided chemical engineering, 32 (23rd European symposium on computer aided process engineering).

Trokanas, N., Raafat, T. Cecelja, F., Kokossis, A., \& Yang A. (2012). Semantic formalism for waste and processing technology classifications using ontology models. In Computer aided chemical engineering. Amsterdam: Elsevier.

UN. (2008). Central product classification (CPC) Ver.2, United Nations.

Van Berkel, R. (2010). Quantifying sustainability benefits of industrial symbioses. Journal of Industrial Ecology, 14(3), 371-373. 